\title{
Functional Polysaccharides as Edible Coatings for Cheese
}

\author{
Miguel A. Cerqueira, ${ }^{* \dagger}{ }^{\dagger}$ Álvaro M. Lima, ${ }^{\ddagger}$ Bartolomeu W. S. Souza, ${ }^{\dagger}$ \\ José A. Teixeira, ${ }^{\dagger}$ Renato A. Moreira, ${ }^{\S}$ And António A. Vicente ${ }^{\dagger}$

\begin{abstract}
IBB, Institute for Biotechnology and Bioengineering, Centre of Biological Engineering, Universidade do Minho, Campus de Gualtar, 4710-057 Braga, Portugal, Departamento de Bioquímica e Biologia Molecular, Universidade Federal do Ceará, Campus do Pici, 60451-970 Fortaleza (CE), Brazil, and
\end{abstract} \\ Centro de Ciências da Saúde, Universidade de Fortaleza, Av. Washington Soares, 1321 Bairro Edson \\ Queiroz, 60811-905 Fortaleza (CE), Brazil
}

\begin{abstract}
The objective of the present study was to apply the polysaccharides from different nontraditional sources for cheese coatings. Chitosan, galactomannan from Gleditsia triacanthos, and agar from Glacilaria birdiae were tested, with different formulations and with the addition of plasticizer and corn oil. The surface properties of the cheese and the wetting capacity of the coatings on the cheese were determined. The three best solutions for each polysaccharide were chosen, further films were cast, and permeability to water vapor, oxygen, and carbon dioxide was determined, along with opacity. The solutions of $G$. triacanthos (formulation: $1.5 \%$ of galactomannan, $2.0 \%$ of glycerol, and $0.5 \%$ of oil) presented the best properties to coat the cheese: $-38.76 \mathrm{mN} \cdot \mathrm{m}^{-1}$ for wettability; $3.24 \times 10^{-11}$ $\left(\mathrm{g} \cdot(\mathrm{m} \cdot \mathrm{s} \cdot \mathrm{Pa})^{-1}\right)$ for water vapor permeability; $0.94 \times 10^{-15}$ and $15.35 \times 10^{-15}\left(\mathrm{~g} \cdot \mathrm{m}\left(\mathrm{Pa} \cdot \mathrm{s} \cdot \mathrm{m}^{2}\right)^{-1}\right)$ for oxygen and carbon dioxide permeabilities, respectively; and opacity values of $5.27 \%$. The $\mathrm{O}_{2}$ consumption and $\mathrm{CO}_{2}$ production rates of the cheese with and without coating were evaluated, showing a decrease of the respiration rates when the coating was applied. The uncoated cheese had an extensive mold growth at the surface when compared with the coated cheese. The results show that these coatings can be applied as an alternative to synthetic coatings.
\end{abstract}

KEYWORDS: Edible coatings; galactomannan; agar; chitosan; cheese

\section{INTRODUCTION}

Consumers and food and packaging industries have joined their efforts to reduce the amount of food packaging materials, because of environmental protection. As an answer to that concern, several issues have to be addressed in order to foster the commercial use of biobased primary food packaging materials. These issues include degradation rates under various conditions, changes in mechanical properties during storage, potential for microbial growth, and release of harmful compounds into the packaged food product (l). However, consumers around the world demand for food of high-quality, without chemical preservatives, and with an extended shelf life. Therefore, an increased effort has been made to develop new natural preservatives and antimicrobials ( 1 ).

The future generation of packaging materials will be derived from renewable resources. These materials will ideally be biodegradable. However, natural polymeric materials vary in

* To whom correspondence should be addressed. Phone: +351.253 . 604400. Fax: +351 0.253.678986. E-mail: miguelcerqueira@ deb.uminho.pt.

${ }^{\dagger}$ Universidade do Minho.

¥ Universidade Federal do Ceará.

${ }^{\S}$ Universidade de Fortaleza. their rate of degradation in the environment, and some proteins, for example, cannot presently be classified as degradable because of standard definitions (1). Edible films and coatings can improve shelf life and food quality by providing good and selective barriers to moisture transfer, oxygen uptake, lipid oxidation, losses of volatile aromas and flavors (2), better visual aspect, and reduction of microbiological contamination (3). The use of coatings creates a modified atmosphere surrounding the commodity similar to that achieved by controlled or modified atmospheric storage conditions. The modified atmosphere created by edible coatings can protect the food from the moment it is applied, through transportation to its final retail destination, and in the home of the consumer $(1,4)$.

Cheese is a complex food product consisting mainly of casein, fat, and water. Several researchers have recommended that fresh cheeses (e.g., cream cheese, decorated cream cheese, soft cheese, and cottage cheese) are packaged in modified atmosphere with $\mathrm{N}_{2}$ and/or $\mathrm{CO}_{2}$ replacing the $\mathrm{O}_{2}$ in the package (5). However, spoilage caused by yeast and especially bacteria may still occur even at very low $\mathrm{O}_{2}$ and elevated $\mathrm{CO}_{2}$ levels (6). Semisoft and hard cheeses (whole, sliced, or shredded) have a relatively high respiration rate, which require a packaging material somewhat permeable to $\mathrm{CO}_{2}$ to avoid an expansion of the packaging. 
Table 1. Spreading Coefficient (Ws) Obtained for the Tested Polysaccharide Solutions on Cheese

\begin{tabular}{|c|c|c|c|c|c|c|c|}
\hline \multirow[b]{2}{*}{ solution } & \multirow[b]{2}{*}{$\begin{array}{c}\text { polysacch. } \\
\text { solutions (w/v) }\end{array}$} & \multirow[b]{2}{*}{$\begin{array}{c}\text { glycerol } \\
(\mathrm{w} / \mathrm{v})\end{array}$} & \multirow[b]{2}{*}{$\begin{array}{c}\text { glycerol/ } \\
\text { sorbitol (w/v) }\end{array}$} & \multirow[b]{2}{*}{ oil $(w / v)$} & \multicolumn{3}{|c|}{ spreading coefficient (Ws) } \\
\hline & & & & & chitosan $^{a}$ & $\begin{array}{c}\text { galactomannan } \\
\text { from } G \text {. triacanthos }{ }^{a}\end{array}$ & $\begin{array}{l}\text { agar from } \\
\text { G. birdiae }\end{array}$ \\
\hline 1 & 0.5 & 0.5 & & & $-28.97 \pm 1.62 a$ & $-42.94 \pm 2.52 \mathrm{a}$ & $-45.85 \pm 3.27 a$ \\
\hline 2 & 0.5 & 2.0 & & & $-29.81 \pm 1.66 a$ & $-57.84 \pm 4.87 b$ & $-36.49 \pm 2.65 b c$ \\
\hline 3 & 0.5 & 0.5 & & 0.5 & $-34.50 \pm 1.50 b$ & $-37.05 \pm 2.59 c$ & $-55.46 \pm 2.33 d$ \\
\hline 4 & 0.5 & 2.0 & & 0.5 & $-35.76 \pm 2.99 b c$ & $-41.69 \pm 2.85 \mathrm{ae}$ & $-47.37 \pm 1.81 \mathrm{ae}$ \\
\hline 5 & 0.5 & & 0.5 & & $-34.46 \pm 2.33 b$ & $-49.69 \pm 4.03 d$ & $-49.62 \pm 1.62 \mathrm{e}$ \\
\hline 6 & 0.5 & & 2.0 & & $-29.96 \pm 3.10 a$ & $-54.79 \pm 0.78 b$ & $-45.69 \pm 2.46 f$ \\
\hline 7 & 0.5 & & 0.5 & 0.5 & $-36.62 \pm 1.89 \mathrm{bcd}$ & $-51.01 \pm 2.37 d$ & $-52.81 \pm 2.34 \mathrm{~d}$ \\
\hline 8 & 0.5 & & 2.0 & 0.5 & $-36.49 \pm 2.19 \mathrm{bcd}$ & $-41.93 \pm 2.77 \mathrm{ae}$ & $-47.97 \pm 1.81 \mathrm{e}$ \\
\hline 9 & 1.5 & 0.5 & & & $-38.31 \pm 2.11 \mathrm{cde}$ & $-58.97 \pm 3.65 b$ & $-39.24 \pm 1.83 \mathrm{gh}$ \\
\hline 10 & 1.5 & 2.0 & & & $-38.95 \pm 1.65 \mathrm{de}$ & $-59.53 \pm 3.65 b$ & $-37.61 \pm 2.16 \mathrm{cgh}$ \\
\hline 11 & 1.5 & 0.5 & & 0.5 & $-34.65 \pm 2.22 b$ & $-59.03 \pm 1.86 b$ & $-30.45 \pm 1.39 j$ \\
\hline 12 & 1.5 & 2.0 & & 0.5 & $-40.13 \pm 2.84 \mathrm{e}$ & $-38.76 \pm 3.38 \mathrm{ce}$ & $-37.52 \pm 1.38 \mathrm{cg}$ \\
\hline 13 & 1.5 & & 0.5 & & $-36.11 \pm 1.98 b c$ & $-56.12 \pm 2.30 \mathrm{~b}$ & $-43.97 \pm 2.85 \mathrm{fi}$ \\
\hline 14 & 1.5 & & 2.0 & & $-49.56 \pm 0.76 f$ & $-55.99 \pm 1.28 b$ & $-46.87 \pm 1.50 \mathrm{a}$ \\
\hline 15 & 1.5 & & 0.5 & 0.5 & $-37.74 \pm 2.48$ cde & $-40.16 \pm 1.40$ ace & $-34.50 \pm 3.41 \mathrm{bj}$ \\
\hline 16 & 1.5 & & 2.0 & 0.5 & $-40.31 \pm 2.64 \mathrm{e}$ & $-41.45 \pm 2.59 \mathrm{ae}$ & $-40.88 \pm 1.14 \mathrm{hi}$ \\
\hline
\end{tabular}

\footnotetext{
${ }^{a}$ Values reported are the means \pm standard deviations $\left(n=20,95 \%\right.$ confidence interval, at $\left.21.4 \pm 0.5^{\circ} \mathrm{C}\right)$. Different letters in the same column indicate a statistically
} significant difference (Tukey test $p<0.05$ ). Bold values are the best values for the same group of polysaccharides.

Meanwhile, $\mathrm{O}_{2}$ must be kept out to avoid fungal spoilage and oxidation of the cheese. Instead, these products require a balanced oxygen and carbon dioxide atmosphere to prolong their shelf life (7).

In semihard cheeses, the factor that most affects cheese stability is water activity $\left(a_{w}\right)$, which depends mainly on moisture and salt contents. During ripening, $a_{w}$ is not constant but decreases until the cheese surface is in equilibrium with the surrounding atmosphere, thus influencing the microbiological and chemical evolution of the cheese (8). Additional environmental factors must be considered in selecting a material for cheese coating (e.g., the light). All of these factors affect not only the cheese's physical characteristics but also its flavor during storage. In fact, many different compounds contribute to cheese flavor, and most of them form during cheese ripening (9).

The cheese studied in this work is a cylindrical, yellow, and semihard cheese; it is sold unpackaged, covered with a synthetic/ antibiotic coating, and under normal storage conditions, it suffers excessive water loss. The present work evaluates the possibility of using functional polysaccharides as coatings on semihard cheese. The choice of the best coating is made taking into consideration its wettability, permeability, and opacity properties. The coating was applied on a cheese without any previous treatment or ripening period. Extreme conditions were used (cheese without ripening, nor treatment; ambient temperature of approximately $22{ }^{\circ} \mathrm{C}$ ) to evaluate how the coating can improve respiration, water loss, and surface spoilage of the cheese.

\section{MATERIALS AND METHODS}

Materials. Edible coating solutions were prepared with chitosan with a degree of deacetylation of approximately 90\% (Aqua Premier Co., Thailand); galactomannan extracted from Gleditsia triacanthos seeds (collected in the Botanic Garden, in Oporto, Portugal, in 2006); agar extracted from Glacilaria birdiae seaweed (specimens of the red seaweed G. birdiae were collected in 2006 on the Atlantic coast of Brazil, Fleixeiras, Trairi - Ceará); corn oil (Sovena, Portugal); 87\% glycerol (Panreac, Spain) and 97\% sorbitol (Acros Organics, Belgium); Tween 80 (Acros Organics, Belgium); lactic acid (Merck, Germany); and distilled water. A commercial semihard cheese was obtained from Queijo Saloio S.A. (Portugal) without any previous treatment (without ripening and coating) two days after production, the samples being stored at $5{ }^{\circ} \mathrm{C}$ and $80 \%$ RH until further use. Regional Saloio cheese is a full fat cheese produced with a mixture of caprine, bovine, and ovine pasteurized milk, which, after coating with a synthetic coating and an antibiotic protector, is submitted to a short ripening period at low temperatures $\left(5\right.$ and $12{ }^{\circ} \mathrm{C}$ in different stages of the ripening process). It requires conditions of $0-22{ }^{\circ} \mathrm{C}$ for sale. The cheese's physicochemical composition is as follows: moisture, $46 \%$; fat, $25 \%$; protein, $18.4 \%$; total ash, $3.58 \%$; chlorides, 1.54 ; $\mathrm{pH} 4.8$; and total acidity, 1.40 (10).

Polysaccharide Extraction. Galactomannan Extraction (G. triacanthos). The polysaccharide extraction was performed as described in Cerqueira et al. (11).

Agar Extraction (G. birdie). The red seaweed was cultivated in the sea using seedlings collected during low tide. The seedlings were cleaned and then tied in a structure made of string, which was placed in the sea, where it was anchored and submerged for two months. The polysaccharide extraction was performed with ethanol (purity $99.8 \%$, Riedel-de Haën, Germany) and distilled water as described by Noseda et al. (12).

Coating and Film Preparation. The coating formulations were based on a two level factorial design with polysaccharide concentrations of $0.5 \%$ and $1.5 \%(\mathrm{w} / \mathrm{v})$, plasticizer concentrations of 0.5 and $2.0 \%$ $(\mathrm{v} / \mathrm{v})$, and oil concentrations of 0 and $0.5 \%(\mathrm{w} / \mathrm{v})$. The coating solutions were prepared dissolving the chitosan $(0.5$ or $1.5 \% \mathrm{w} / \mathrm{v})$ in a $1.0 \%$ $(\mathrm{v} / \mathrm{v})$ lactic acid solution with agitation using a magnetic stirrer during $2 \mathrm{~h}$ at room temperature $\left(20{ }^{\circ} \mathrm{C}\right)$; Tween 80 was also added as a surfactant at concentrations of $0.2 \%(\mathrm{w} / \mathrm{v})$. Corn oil was added in concentrations of $0.5 \%(\mathrm{w} / \mathrm{v})$, with agitation during $20 \mathrm{~min}$ at $60{ }^{\circ} \mathrm{C}$. As plasticizers, glycerol and a mixture of glycerol/sorbitol (50:50) were added at concentrations between 0.5 and $2.0 \%$ (w/v).

The coating solutions from galactomannan of G. triacanthos (GT) were prepared by dissolving the galactomannan $(0.5$ or $1.5 \% \mathrm{w} / \mathrm{v})$ in distilled water with agitation using a magnetic stirrer during $2 \mathrm{~h}$ at room temperature $\left(20^{\circ} \mathrm{C}\right)$. As plasticizers, glycerol and a mixture of glycerol/sorbitol (50:50) were added at concentrations between $0.5-2.0 \%$ (w/v). Corn oil was added at concentrations of $0.5 \%$ (w/v), with agitation during $20 \mathrm{~min}$ at $60{ }^{\circ} \mathrm{C}$.

The coating solutions from agar of $G$. birdiae $(\mathrm{GB})$ were prepared dissolving the agar $(0.5$ or $1.5 \% \mathrm{w} / \mathrm{v})$ in distilled water with agitation using a magnetic stirrer during $20 \mathrm{~min}$ at $60^{\circ} \mathrm{C}$. As plasticizers, glycerol and a mixture of glycerol/sorbitol (50:50) were added at concentrations between 0.5 and $2.0 \%(\mathrm{w} / \mathrm{v})$. Corn oil was added at a concentration of $0.5 \%(\mathrm{w} / \mathrm{v})$.

In all cases, a constant amount $(13 \mathrm{~mL})$ of solution was cast onto a $5.7 \mathrm{~cm}$ diameter glass plate in order to maintain film thickness. The films were dried in an oven at $35{ }^{\circ} \mathrm{C}$ during $16 \mathrm{~h}$. These solutions correspond to solutions 1-16, in Table 1. 
Films were maintained at $20{ }^{\circ} \mathrm{C}$ and $50 \%$ RH before permeability and opacity tests. (These were the average conditions at the laboratory, as maintained by the existing temperature and humidity control system).

Film Thickness. The film thickness was measured with a digital micrometer (No. 293-561, Mitutoyo, Japan). Five thickness measurements were taken on each testing sample at different points, and the mean values were used for the calculation of water vapor permeability $(W V P)$, oxygen permeability $\left(\mathrm{O}_{2} \mathrm{P}\right)$, and dioxide carbon permeability $\left(\mathrm{CO}_{2} \mathrm{P}\right)$.

Critical Surface Tension and Surface Tension of Cheese Skin. According to Zisman (13), in systems having a surface tension lower than $100 \mathrm{mN} \cdot \mathrm{m}^{-1}$ (low-energy surfaces), the contact angle formed by a drop of liquid on a solid surface will be a linear function of the surface tension of the liquid, $\gamma_{L V}$ (where phase $V$ is air saturated with the vapor of liquid, $L$ ). The Zisman method, briefly described below, is applicable only for low energy surfaces; therefore, it is necessary to determine the surface energy of the cheese.

For a pure liquid, if polar $\left(\gamma_{L}^{p}\right)$ and dispersive $\left(\gamma_{L}^{d}\right)$ interactions are known, and if $\theta$ is the contact angle between that liquid and a solid, the interaction can be described in terms of the reversible work of adhesion, $W a$, as follows:

$$
W_{a}=W_{a}^{d}+W_{a}^{p} \Leftrightarrow W_{a}=2\left(\sqrt{\gamma_{s}^{d} \cdot \gamma_{L}^{d}}+\sqrt{\gamma_{s}^{p} \cdot \gamma_{L}^{p}}\right)
$$

where $\gamma_{S}^{p}$ and $\gamma_{S}^{d}$ are the polar and dispersive contributions of the surface of the studied solid. Rearranging eq 1 yields

$$
\frac{1+\cos \theta}{2} \cdot \frac{\gamma_{L}}{\sqrt{\gamma_{L}^{d}}}=\sqrt{\gamma_{s}^{p}} \cdot \sqrt{\frac{\gamma_{L}^{p}}{\gamma_{L}^{d}}}+\sqrt{\gamma_{s}^{d}}
$$

The contact angle determinations of at least three pure compounds, bromonaphthalene (Merck, Germany), formamide (Merck, Germany), and ultra pure water, on the surface of the cheese (cheese skin) combined with the values presented below will allow the calculation of both the independent variable, $\left(\gamma_{L}^{p}\right) /\left(\gamma_{L}^{d}\right)^{1 / 2}$, and the dependent variable, $\left.(1+\cos \theta) /(2) \cdot\left(\gamma_{L}\right) /\left(\gamma_{L}^{d}\right)^{1 / 2}\right)$, from eq 2 .

The surface tension and the dispersive and the polar component were, respectively, $72.10,19.90$, and $52.20 \mathrm{mN} \cdot \mathrm{m}^{-1}$ for water, $44.40,44.40$, and $0.00 \mathrm{mN} \cdot \mathrm{m}^{-1}$ for bromonaphtalene and $56.90,23.50$, and 33.40 $\mathrm{mN} \cdot \mathrm{m}^{-1}$ for formamide (14).

The estimation of the critical surface tension $\left(\gamma_{C}\right)$ was performed by extrapolation from Zisman plots (13). Zisman plots have long been used to characterize the wettability of low-energy surfaces. Zisman plots are obtained by plotting the cosine of the contact angle of pure liquids on a solid surface to be studied against the surface tension of the same series of liquids. The intercept of these curves with $\cos \theta=1$ is known as the critical surface tension $\left(\gamma_{C}\right)$. The critical surface tension is an imaginary point of the $\gamma_{s v}$ value, and it is frequently used to describe the wettability of a surface. It represents the value of $\gamma_{L V}$ of a liquid above which the spreading of this liquid in a solid surface is complete. The critical surface tension $\left(\gamma_{C}\right)$ is defined as follows:

$$
\gamma_{C}=\lim \gamma_{L V} \text { as } \theta \rightarrow 0
$$

All experiments were performed at $21.3 \pm 0.2{ }^{\circ} \mathrm{C}$ with 20 replicates for each of the compounds used.

Wettability. The wettability was studied by determining the values of the spreading coefficient (Ws) and the works of adhesion $(W a)$ and cohesion $(W c)$. The adhesive forces promote the liquid spreading on a solid surface and the cohesive forces promote their contraction. The wetting behavior of the solutions will mainly depend on the balance between these forces. The surface tension of the coating solution was measured by the pendant drop method using the Laplace-Young approximation (15).

The contact angle $(\theta)$ of a liquid drop on a solid surface is defined by the mechanical equilibrium of the drop under the action of three interfacial tensions: solid-vapor $\left(\gamma_{S V}\right)$, solid-liquid $\left(\gamma_{S L}\right)$, and liquid-vapor $\left(\gamma_{L V}\right)$. The equilibrium spreading coefficient $(W s)$ is defined by eq 4 (16) and can only be negative or zero.

$$
W_{s}=W_{a}-W_{c}=\gamma_{S V}-\gamma_{L V}-\gamma_{S L}
$$

where $W a$ and $W c$ are the works of adhesion and cohesion, defined by eqs 5 and 6 , respectively.

$$
\begin{gathered}
W_{a}=\gamma_{L V}+\gamma_{S V}-\gamma_{S L} \\
W_{c}=2 \cdot \gamma_{L V}
\end{gathered}
$$

Contact angle $(\theta)$ and liquid-vapor surface tension $\left(\gamma_{L V}\right)$ were measured by a face contact angle meter (OCA 20, Dataphysics, Germany). The samples of the coatings were taken with a $500 \mu \mathrm{L}$ syringe (Hamilton, Switzerland), with a needle of $0.75 \mathrm{~mm}$ diameter. The contact angle at the cheese surface was measured by the sessile drop method (17). Measurements were made in less than $30 \mathrm{~s}$. Ten replicates of contact angle and surface tension measurements were obtained at $21.3 \pm 0.5^{\circ} \mathrm{C}$.

Water Vapor Permeability Measurement (WVP). The measurement of water vapor permeability $(W V P)$ was determined gravimetrically on the basis of the ASTM E96-92 method (18). The film was sealed on the top of a permeation cell containing distilled water $(100 \%$ $\mathrm{RH} ; 2337 \mathrm{~Pa}$ vapor pressure at $20^{\circ} \mathrm{C}$ ), placed in a desiccator at $20^{\circ} \mathrm{C}$ and $0 \%$ RH (0 Pa water vapor pressure) containing silica. The cells were weighed at intervals of $2 \mathrm{~h}$ during $10 \mathrm{~h}$. Steady-state and uniform water pressure conditions were assumed by keeping the air circulation constant outside the test cell by using a miniature fan inside the desiccator. The slope of weight loss versus time was obtained by linear regression. Three replicates were obtained for each film.

Oxygen and Carbon Dioxide Permeability. Oxygen permeability $\left(\mathrm{O}_{2} \mathrm{P}\right)$ and carbon dioxide permeability $\left(\mathrm{CO}_{2} \mathrm{P}\right)$ were determined on the basis of the ASTM D 3985-02 (2002) method (19). The films were sealed between two chambers, each one having two channels. In the lower chamber, $\mathrm{O}_{2}$ (or $\mathrm{CO}_{2}$ ) was supplied at a controlled ( $\mathrm{J} \& \mathrm{~W}$ Scientific, ADM 2000, USA) flow rate to keep its pressure constant in that compartment. The other chamber was purged by a stream of nitrogen, also at controlled flow. Nitrogen acted as a carrier for the $\mathrm{O}_{2}$ (or the $\mathrm{CO}_{2}$ ).

In the case of the $O_{2} P$ measurement, the flow leaving this chamber was connected to an $\mathrm{O}_{2}$ sensor (Mettler Toledo, Suisse), which measured the $\mathrm{O}_{2}$ concentration in that flow online. In the case of the $\mathrm{CO}_{2} \mathrm{P}$ measurement, the flow leaving this chamber was collected in a syringe for $\mathrm{CO}_{2}$ quantification. To determine $\mathrm{CO}_{2}$ concentration, $1 \mathrm{~mL}$ of sample was injected in a gas chromatograph (Chrompack 9001, Middelburg, Netherlands) at $110{ }^{\circ} \mathrm{C}$ with a column Porapak Q 80/100 mesh $2 \mathrm{~m} \times$ $1 / 8^{\prime \prime} \times 2 \mathrm{~mm} \mathrm{SS}$, using a flame ionization detector (FID) at $110^{\circ} \mathrm{C}$. Helium at $23 \mathrm{~mL} \cdot \mathrm{min}^{-1}$ was used as carrier gas. A standard mixture containing $10 \% \mathrm{CO}_{2}, 20 \% \mathrm{O}_{2}$, and $70 \% \mathrm{~N}_{2}$ was used for calibration.

The flows of the two chambers were connected to a manometer to ensure the equality of pressures (both at $1 \mathrm{~atm}$ ) between both compartments. As the $\mathrm{O}_{2}$ (and the $\mathrm{CO}_{2}$ ) was carried continuously by the nitrogen flow, it was considered that $\mathrm{O}_{2}$ (and the $\mathrm{CO}_{2}$ ) partial pressure in the upper compartment is null, and therefore, $\Delta P$ is equal to $1 \mathrm{~atm}$. Three replicates were obtained for each sample, in each case $\left(\mathrm{O}_{2} \mathrm{P}\right.$ and $\left.\mathrm{CO}_{2} \mathrm{P}\right)$.

Opacity. The opacity of the samples was determined according to the Hunter laboratory method, with a Minolta colorimeter (CR 300; Minolta, Japan), as the relationship between the opacity of each sample on the black standard $\left(Y_{b}\right)$ and the opacity of each sample on the white standard $\left(Y_{w}\right)$.

Cheese Coating. The semihard cheeses, with approximately $270 \mathrm{~g}$, were coated with the selected solution by brushing the surface until all of it was covered, the residual coating being allowed to drip off. Cheeses were left for $4 \mathrm{~h}$ at $4{ }^{\circ} \mathrm{C}$ until the coating was dry.

$\mathrm{O}_{2}$ and $\mathrm{CO}_{2}$ Exchange Rates. The closed system method with air as initial atmosphere was used for the measurement of the gas exchange rate of the whole cheese. The whole cheese was placed inside a hermetic jar at a temperature of $21.86 \pm 0.76{ }^{\circ} \mathrm{C}$ and an initial relative humidity of $70 \%$. The jar was closed, and air circulation was promoted inside it by using a miniature fan. The atmosphere inside the jar was measured by drawing gas samples with a $1 \mathrm{~mL}$ syringe through a septum fitted in the jar lid. The $\mathrm{O}_{2}$ and $\mathrm{CO}_{2}$ contents in the jar were determined using a gas chromatograph (Chrompack 9001, Middelburg, Netherlands) 
at $110{ }^{\circ} \mathrm{C}$ with a column molecular sieve 5A 80/100 mesh $1 \mathrm{~m} \times 1 / 8^{\prime \prime}$ $\times 2 \mathrm{~mm}$ to separate the $\mathrm{O}_{2}$ and a column Porapak Q 80/ 100 mesh $2 \mathrm{~m}$ $\times 1 / 8^{\prime \prime} \times 2 \mathrm{~mm}$ SS to separate the $\mathrm{CO}_{2}$ using a flame ionization detector (FID) at $110^{\circ} \mathrm{C}$. Helium at $23 \mathrm{~mL} \cdot \mathrm{min}^{-1}$ was used as carrier gas. A mixture containing $10 \% \mathrm{CO}_{2}, 20 \% \mathrm{O}_{2}$, and $70 \% \mathrm{~N}_{2}$ was used as the standard for calibration. Two replicates of each condition were measured during $48 \mathrm{~h}$.

The $\mathrm{O}_{2}$ consumption and $\mathrm{CO}_{2}$ production rates were determined applying eqs 7 and 8 (20), developed for a closed system impermeable to gases.

$$
\begin{aligned}
& \mathrm{d} y_{O_{2}}=-R_{O_{2}} \frac{w}{V_{f}} \mathrm{~d} t \\
& \mathrm{~d} y_{\mathrm{CO}_{2}}=R_{\mathrm{CO}_{2}} \frac{w}{V_{f}} \mathrm{~d} t
\end{aligned}
$$

where, $R_{O 2}$ is the $\mathrm{O}_{2}$ consumption rate, $\mathrm{mL}\left[\mathrm{O}_{2}\right] \cdot \mathrm{kg}^{-1} \cdot \mathrm{h}^{-1}, R_{\mathrm{CO} 2}$ is the $\mathrm{CO}_{2}$ production rate, $\mathrm{mL}\left[\mathrm{CO}_{2}\right] \cdot \mathrm{kg}^{-1} \cdot \mathrm{h}^{-1}, w(\mathrm{~kg})$ is the weight of the cheese, and $V_{f}(\mathrm{~mL})$ is the free volume of the container. The free volume $V_{f}$ of the package is calculated by

$$
V_{f}=V_{p}-\frac{w}{\rho_{c h}}
$$

where, $V_{p}(\mathrm{~mL})$ is the total volume of the container, $w(\mathrm{~kg})$ is the weight of the cheese, and $\rho_{c h}$ is the true density of the cheese, in this case $1.095 \times 10^{-3} \mathrm{~kg} \cdot \mathrm{mL}^{-1}$, obtained experimentally following the method described by Owolarafe et al. (21). The graph of $\mathrm{O}_{2}$ consumed versus time or $\mathrm{CO}_{2}$ produced versus time was used to calculate the slopes, which correspond to the derivatives, $\mathrm{d} y_{\mathrm{O}_{2}} / \mathrm{d} t$ (or $\mathrm{d} y_{\mathrm{CO}_{2}} / \mathrm{d} t$ ).

Weight Loss and Relative Humidity. The weight loss and relative humidity were measured in parallel to the measurements of $\mathrm{O}_{2}$ and $\mathrm{CO}_{2}$ exchange rates. The cheese was weighed at the beginning of the experiment $(I W)$ and at the end $(F W)$, the results expressed as the relative weight loss $(R W L)$ defined as

$$
R W L=\frac{I W-F W}{I W} \cdot 100
$$

The change in relative humidity $(R H)$ of the atmosphere of the jar was followed using a sensor (hygrometer HD $8501 \mathrm{H}$ ) fitted inside the jar.

Cheese Surface. The surface of the cheese was inspected for the appearance of molds at the end of the $\mathrm{O}_{2}$ and $\mathrm{CO}_{2}$ exchange rate determination $(22,23)$.

Statistical Analyses. Statistical analyses were performed using Analysis of Variance (ANOVA) and linear regression analysis. The Tukey test $(\alpha=0.05)$ was used to determine any significance of differences between specific means (SigmaStat, trial version, 2003, USA).

\section{RESULTS AND DISCUSSION}

Critical Surface Tension and Surface Tension of Cheese. The determination of the surface tension and of the critical surface tension of the cheese allows the characterization of the surface of its skin. According to Zisman (17), in systems having a surface tension lower than $100 \mathrm{mN} \cdot \mathrm{m}^{-1}$ (low energy surfaces), the contact angle formed by a drop of liquid on a solid surface will be a linear function of the surface tension of the liquid, $\gamma_{L V}$ (where phase $V$ is air saturated with the vapor of liquid, $L$ ), which allows the application of the method to determine the wettability.

The surface from the cheese displays values of critical surface and surface tension of $18.33 \pm 0.10 \mathrm{mN} \cdot \mathrm{m}^{-1}$ and $37.79 \pm 0.76$ $\mathrm{mN} \cdot \mathrm{m}^{-1}$, respectively. The cheese surface is a low-energy surface $\left(<100 \mathrm{mN} \cdot \mathrm{m}^{-1}\right)$ and presents a higher dispersive component $\left(29.93 \pm 0.41 \mathrm{mN} \cdot \mathrm{m}^{-1}\right)$, which shows its ability to participate in nonpolar interactions, and a low polar component $\left(7.87 \pm 0.37 \mathrm{mN} \cdot \mathrm{m}^{-1}\right)$. A surface with these characteristics interacts with liquid primarily by dispersion forces, influencing the effective spreading of the coating on the cheese surface. The compatibility of the polarity (apolar or polar) of the surface and of the coating may therefore play an important role in the wettability of the surface. The cheese, being very rich in apolar components (e.g., fat), features a significant apolar influence.

Wettability. The wettability was studied by determining the values of the spreading coefficient $(W s)$. Wettability is one of the most important properties when evaluating the capacity of a solution to coat a designated surface. In practical terms, the closer the $W s$ values are to zero, the better a surface will be coated. The results show (Table 1) that depending on the amount of polysaccharide, plasticizer, and oil added, the values of $W s$ are statistically different. Considering the solutions tested, the best (higher) value of $W s$ on the cheese surface was determined for each polysaccharide (Tukey test, $p<0.05$ ). The best values are shown in bold. (When two or more values are shown in bold for the same polysaccharide, it means that those values are statistically equal).

In chitosan coating solutions, the use of Tween 80 was necessary to increase the otherwise very low values of $W s$ (results not shown). The improvement of $W s$ with the addition of Tween 80 was also shown by Ribeiro et al. (4). Tween 80 acts by reducing the superficial tension of the liquid and by increasing the value of $W s$, therefore improving the compatibility between the solution and the cheese surface. The results obtained demonstrate that chitosan solutions with lower concentration of chitosan and without oil present better values of Ws. Solutions 1,2 , and 6 do not present a statistically significant difference (Table 1). The higher values of $W s$ of the solutions with lower chitosan concentrations can be explained by the high ratio between the concentration of Tween 80 (which acts by reducing the superficial tension of the liquid) and the concentration of chitosan. The incorporation of oil to the solution of chitosan, in the presence of Tween 80 , will form a micellar structure, the interaction between chitosan and oil made through the hydrophilic and hydrophobic parts of the Tween 80 molecule, respectively; this will contribute to the increase of the superficial tension of the liquid once Tween 80 molecules are occupied in the micelles and are no longer available to reduce the superficial tension of the liquid.

In the case of $G$. triacanthos, the solutions with higher values of Ws were those containing oil. Solutions 3, 12, and 15 (Table 1) do not present a statistically significant difference. The presence of oil in G. triacanthos coatings decreased the values of Ws. The partly hydrophobic surface of the cheese, as explained previously, presents a good adhesion to the solutions of $G$. triacanthos containing oil, eventually due to the ability of the solution with oil (more hydrophobic) to interact with the cheese surface (24).

For the solutions made with $G$. birdiae, solution 11 was the best, presenting statistically significant differences from the other samples (Table 1). As in previous cases, the solutions containing oil present the best value of Ws.

When there were no statistically significant differences between polysaccharide solutions, it has been assumed that both were equally good in terms of wettability and that their differentiation must be made on the basis of other criteria (such as water vapor, $\mathrm{O}_{2}$, and $\mathrm{CO}_{2}$ permeability and opacity).

Water Vapor Permeability (WVP). The water vapor permeability is the most extensively studied property of edible films mainly because of the importance of the water in deteriorative reactions. The three best solutions of chitosan (C) in terms of wettability were subsequently analyzed for WVP. Table 2 shows 
Table 2. Values of Water, $\mathrm{O}_{2}, \mathrm{CO}_{2}$ Permeability, and Opacity of the Films

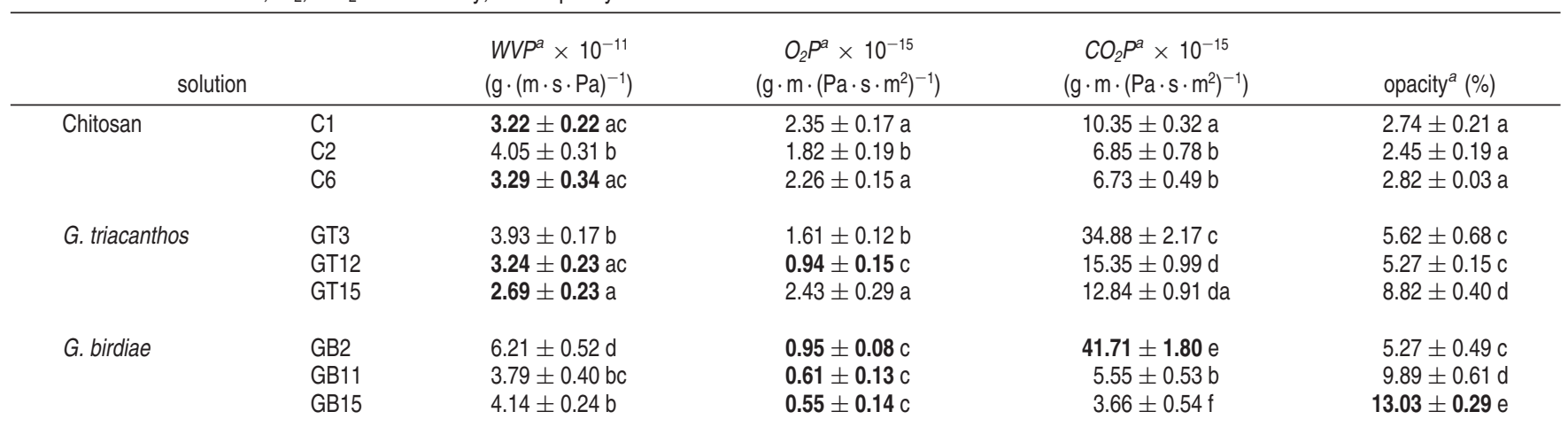

${ }^{a}$ Values reported are the means \pm standard deviations ( $n=5,95 \%$ confidence interval). Different letters in the same column indicate a statistically significant difference (Tukey test $p<0.05$ ). Bold values are the best values.

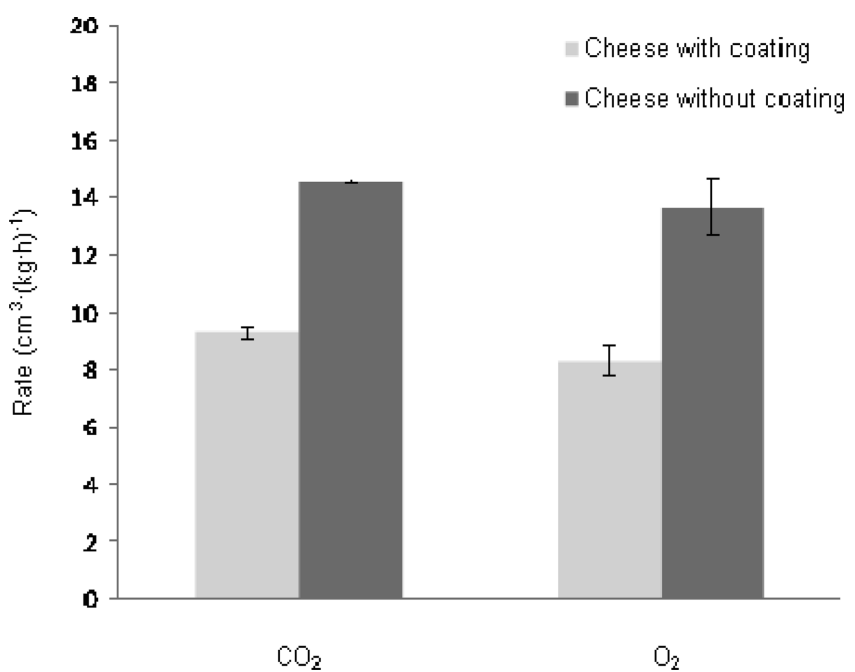

Figure 1. $\mathrm{O}_{2}$ and $\mathrm{CO}_{2}$ transfer rates in cheese at $21.86 \pm 0.76{ }^{\circ} \mathrm{C}(n=$ 2, $95 \%$ confidence level).

that the values of WVP change with the integration of sorbitol and with different concentrations of glycerol. With the addition of sorbitol, the WVP decreases, and this observation is in agreement with the conclusions of Garcia et al. (25) and Hernandez-Muñoz et al. (26). Table 2 shows that $W V P$ for films from solution $\mathrm{C} 2$ is statistically significant different from that of the other two ( $\mathrm{C} 1$ and $\mathrm{C} 6)$, presenting a higher value of $W V P$. Although an increase of the mean value of $W V P$ is observable due to the increase of glycerol concentration (from solution $\mathrm{C} 1$ to solution $\mathrm{C} 2$ ), the difference is statistically significant.

The same procedure was adopted for G. triacanthos (GT) solutions GT3, GT12, and GT15. Films from solutions GT12 and GT15 showed a lower value of WVP without a statistically significant difference, while the value of $W V P$ for the films from solution GT15 is significantly different from those obtained with solution GT3 (Table 2). An increase of the concentration of GT galactomannan corresponds to a decrease of $W V P$, presumably due to a stronger gel network, where the polysaccharide molecules are closer together. Furthermore, the solution with sorbitol (GT15) showed the lowest value of WVP; this observation may be explained by the larger size and lower hygroscopicity of the sorbitol compared to those of glycerol, reducing its ability to affect hydrogen bonding between polysaccharide chains (27).

Table 2 also shows the values of $W V P$ for the best solutions of G. birdiae (GB2, GB11, and GB15). The lower WVP values were registered for films from solutions GB11 and GB15, which are not statistically different but have a statistically significant difference with solution GB2. In parallel to what happened with the films from solutions of $G$. triacanthos, increasing the concentration of $G$. birdiae led to lower values of $W V P$.

The addition of oil promoted a decrease of WVP in both $G$. triacanthos and $G$. birdiae films. In this line, Hernandez-Muñoz et al. (26) indicated that WVP occurs through the hydrophilic portion of the film; therefore, depending on the hydrophilichydrophobic ratio of the films, Avena-Bustillos et al. (28) showed that WVP decreases with the addition of beeswax to sodium caseinate films. Also, Péroval et al. (29) showed that arabinoxylan films with hydrogenated palm oil have lower WVP values than films without oil. Pranoto et al. (30) showed similar results with alginate-based films containing garlic oil.

Oxygen Permeability $\left(\boldsymbol{O}_{2} \boldsymbol{P}\right)$. Oxygen is the key factor in cheese preservation. Films that provide a proper oxygen barrier can help improve food quality and extending food shelf life. Table 2 presents the values of $\mathrm{O}_{2} \mathrm{P}$ of the analyzed samples. In the case of chitosan films, the samples with higher concentration of plasticizer have statistically higher values of $\mathrm{O}_{2} \mathrm{P}$ than the samples with lower concentration, which were also shown by Caner et al. (31). The plasticizer decreases the intermolecular attractions between polymeric chains, facilitating the penetration of gas molecules (2). However, the partial replacement of glycerol by sorbitol provoked an increase of the $\mathrm{O}_{2} \mathrm{P}$ value, as can be observed when comparing the results for films from solutions C2 and C6. As mentioned before, this difference can be explained by the different molecular size and hygroscopicity of sorbitol and glycerol (27).

Films from solution GT12 show the lower value (significantly different) of $\mathrm{O}_{2} \mathrm{P}$, corresponding to the higher concentration of plasticizer and also to the higher concentration of G. triacanthos galactomannan. It is known that the increase of galactomannan concentration contributes to the decrease of permeability, while it is normally accepted that a higher concentration of glycerol increases $\mathrm{O}_{2} \mathrm{P}$. In the present case, the effect of the galactomannan concentration seems to have surpassed the effect of glycerol concentration, contrary to what has been observed for the solutions of chitosan. Garcia et al. (25) found similar results for starch-based films and explained their results by stating that the addition of plasticizer decreases the presence of pores and cracks, improving dispersion and decreasing gas permeability. There were no statistically significant differences for the films from solutions of $\mathrm{G}$. birdiae in terms of $\mathrm{O}_{2} \mathrm{P}$ (Table 2), having lower values when compared with the films of GT and C.

Carbon Dioxide Permeability $\left(\mathrm{CO}_{2} \mathrm{P}\right)$. Table 2 shows the comparison of $\mathrm{CO}_{2}$ permeability values for the different polysaccharides. The chitosan films displayed lower values of $\mathrm{CO}_{2} \mathrm{P}$, and the different films of $\mathrm{C}$ do not present a statistically 


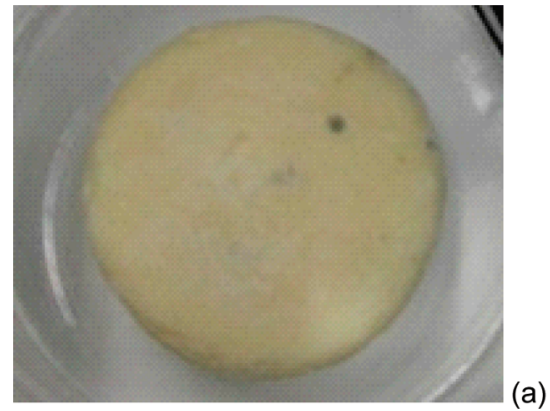

Figure 2. Cheese in a jar, with coating (a) and without coating (b).

significant difference. The film from solutions C2, however, shows the lower value. These results seem to indicate that solutions with a higher concentration of plasticizer produce films with a lower value of $\mathrm{CO}_{2} \mathrm{P}$. The addition of plasticizer decreases the presence of pores and cracks, improving the dispersion and decreasing the gas permeability (25).

For $G$. triacanthos films, the increase of the polysaccharide concentration and the addition of sorbitol provoked a decrease of $\mathrm{CO}_{2} \mathrm{P}$. Films from solution GT3 show a statistically significant difference from those of solutions GT12 and GT15 (Table 2).

$G$. birdiae films display a very significant decrease of the value of $\mathrm{CO}_{2} \mathrm{P}$ with the increase of polysaccharide concentration. Also here, the addition of sorbitol decreases the value of $\mathrm{CO}_{2} \mathrm{P}$, as shown by Garcia et al. (25). The effect of polysaccharide concentration seems to be, by far, the most important one affecting $\mathrm{CO}_{2} \mathrm{P}$.

Opacity. The opacity means a smaller transparency, important to control the incidence of light on the cheese (32). Opacity values increase with the concentration in polysaccharide for films from solutions of GT and GB, the solutions with sorbitol and oil being those with a higher value of opacity. The addition of lipid caused the films to become whitish. Table 2 shows that the incorporation of corn oil in the films increased the opacity. Yang et al. (33) demonstrated that gellan film also has increased opacity with the increase of lipid concentration.

Criteria for Choosing a Coating. When choosing an adequate coating composition for the cheese under consideration, there are a number of criteria that should be met. Some of those (such as wettability) have already been considered. Others, such as gas transport properties and opacity, should be met in order to (i) decrease the water loss of the cheese (i.e, lower $W V P$ values); (ii) decrease the $\mathrm{O}_{2}$ permeability (i.e., lower $\mathrm{O}_{2} \mathrm{P}$ values), once the oxygen in contact with the cheese contributes to the oxidation of fats and to the growth of undesirable microorganisms (13); (iii) increase the shelf life of cheese, by increasing the lag-phase for the growth of coliforms (and other Gram-negative spoilage bacteria), yeasts and molds (9), i.e., high $\mathrm{CO}_{2} \mathrm{P}$ values; and (iv) decrease the light incidence in the cheese (light promotes fat oxidation) (13), i.e., high values of opacity. Having in mind the criteria explained above, it is possible to select the best values of the permeability for water vapor, $\mathrm{O}_{2}$, and $\mathrm{CO}_{2}$, and opacity (Table 2).

In Table 2, the variables ( $W V P, \mathrm{O}_{2} \mathrm{P}$, and $\mathrm{CO}_{2} \mathrm{P}$, opacity) were placed by decreasing order of importance, and solution GT12 was chosen as the best option for coating cheese despite the fact that its value of $\mathrm{CO}_{2} \mathrm{P}$ was not the highest among those determined in this work. In fact, previous works have shown that there are advantages and disadvantages both for low and high $\mathrm{CO}_{2} \mathrm{P}$ values (34), thus justifying the choice for an intermediate one.

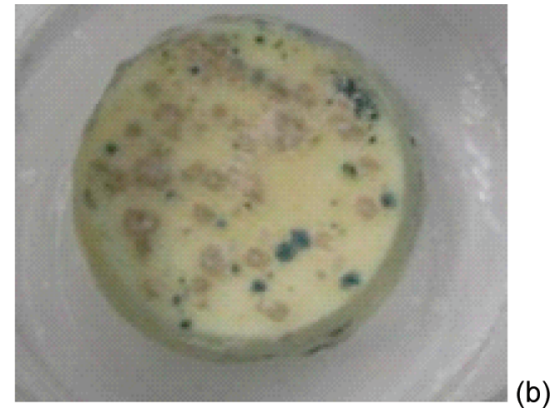

$\mathrm{O}_{2}$ and $\mathrm{CO}_{2}$ Transfer Rates in Cheese. To understand how the GT coating solution can improve water loss and gas exchange, the whole cheese was coated using a solution with the formulation of GT12, and $\mathrm{O}_{2}$ and $\mathrm{CO}_{2}$ transfer rates were compared with those of the cheese without coating.

The concentration of the gases was measured during $48 \mathrm{~h}$, the gas transfer rate was calculated, and the results are presented in Figure 1. The coated cheese clearly displays a lower gas exchange rate, and it is also clear that the rate of $\mathrm{CO}_{2}$ production is higher than that of $\mathrm{O}_{2}$ consumption.

The obtained values for the $\mathrm{O}_{2}$ consumption rate ranged between 13.65 and $8.33 \mathrm{~mL} \cdot \mathrm{kg}^{-1} \cdot \mathrm{h}^{-1}$, while the $\mathrm{CO}_{2}$ production rate ranged between 14.52 and $9.27 \mathrm{~mL} \cdot \mathrm{kg}^{-1} \cdot \mathrm{h}^{-1}$ for uncoated and coated cheese, respectively. These values are high when compared with those of other cheese types. Fedio et al. (35) studied the gas exchange in Swiss cheese, and they found values ranging from 1 to $2 \mathrm{~mL} \cdot \mathrm{kg}^{-1} \cdot \mathrm{h}^{-1}$. These values are difficult to compare, however, because of differences in cheese composition and in the extent of cheese maturation (e.g., ours was not subjected to maturation). The presence of molds in the surface of the cheese may also be related to the differences found: the coated cheese with less molds at the surface showed lower values of $\mathrm{RO}_{2}$ and $\mathrm{RCO}_{2}$.

Weight Loss and Surface Evaluation. The coated cheese presents a relative weight loss of $0.11 \pm 0.04 \%$, while the cheese without coating loses $0.84 \pm 0.07 \%$. Therefore, the coating allows a decrease in weight loss (ca. 8-fold the value in the absence of coating).

During the experiments, the values of relative humidity inside the jar increased rapidly, and at the end of the experiment, a value of $100 \%$ was reached. After $48 \mathrm{~h}$ from the beginning of the experiment, the cheese began to show fungal growth at the surface, mostly occurring on the uncoated cheese. Visual evaluation confirmed that the uncoated cheese had extensive mold growth with almost the entire surface covered with mold colonies after only $48 \mathrm{~h}$ (Figure 2). The coating solution GT12 appears to have inhibited the growth of molds, when compared with uncoated cheese. Further work has to be made to confirm the suitability of this coating to increase the shelf life of cheese after ripening and at different storage temperatures.

In conclusion, the cheese with coating has lower gas transfer rates as well as a decrease of the relative weight loss (ca. 8-fold less the value in the absence of coating). Visual evaluation also confirmed that the uncoated cheese suffered from an extensive mold growth when compared with the coated cheese.

The present work can serve as a guide for the use of new coatings for cheese as alternatives to synthetic coatings and may also be a guide for the study of future new materials for this purpose. 


\section{ACKNOWLEDGMENT}

We thank Queijo Saloio S.A. for all the support concerning the supply of the cheese samples.

\section{LITERATURE CITED}

(1) Lin, D.; Zhao, Y. Innovations in the development and application of edible coatings for fresh and minimally processed fruits and vegetables. CRFSFS 2007, 6, 60-75.

(2) Kester, J. J.; Fennema, O. R. Edible film and coatings: a review. Food Technol. 1986, 40, 47-59.

(3) Nisperos-Carriedo, M. O. Edible Coatings and Films Based on Polysaccharides. In Edible Coatings and Films to Improve Food Quality; Krochta, J. M., Baldiw, E. A., Nisperos-Carriedo, M., Eds.; Technomic Publishing Company, Inc.: Lancaster, PA, 1994; pp 305-335.

(4) Ribeiro, C.; Vicente, A. A.; Teixeira, J. A.; Miranda, C. Optimization of edible coating composition to retard strawberry fruit senescence. Postharvest Biol. Technol. 2007, 44, 63-70.

(5) Mannheim, C. M.; Soffer, T. Shelf-life extension of cottage cheese by modified atmosphere packaging. Lebensm.-Wiss. Technol. 1996, 29, 767-771.

(6) Westall, S.; Filtenborg, O. Spoilage yeasts of decorated soft cheese packed in modified atmosphere. Food Microbiol. 1998, 15, 243 249.

(7) Haasum, I.; Nielsen, P. V. Physiological characterization of common fungi associated with cheese. J. Food Sci. 1998, 63, 157161.

(8) Saurel, R.; Pajonk, A.; Andrieu, J. Modelling of French Emmental cheese water activity during salting and ripening periods. J. Food Eng. 2004, 63, 163-170.

(9) Robertson, G. L. Packaging of Dairy Products. In Food Packaging: Principles and Practice; Robertson, G. L., Ed.; CRC/Taylor \& Francis: Boca Raton, FL, 2006; pp 400-415.

(10) Pantaleão, I.; Pintado, M. M. E.; Poças, M. F. F. Evaluation of two packaging systems for regional cheese. Food Chem. 2007, 102, 481-487.

(11) Cerqueira, M. A.; Pinheiro, A. C.; Souza, B. W. S.; Lima, A. M. P.; Riberio, C.; Miranda, C.; Teixeira, J. A.; Moreira, R. A.; Coimbra, M. A.; Gonçalves, M. P.; Vicente, A. A. Extraction, purification and characterization of galactomannans from nontraditional sources. Carbohydr. Polym. 2009, 77, 408-414.

(12) Noseda, M. D.; Tulio, S.; Duarte, M. E. R. Polysaccharides from the red seaweed Bostrychia montagnei: chemical characterization. J. Appl. Phycol. 1999, 11, 35-40.

(13) Zisman, W. A. Contact Angle, Wettability and Adhesion; Fowkes, F. M. Advances in Chemistry Series; American Chemical Society: Washington, DC, 1964. Vol. 43, pp 1-51.

(14) Busscher, H. J.; Van Pelt, A. W.; de Boer, P.; de Jong, H. P.; Arends, J. The effect of surface roughening of polymers on measured contact angles of liquids. Colloids Surf. 1984, 9, 319331.

(15) Song, B.; Springer, J. Determination of interfacial tension from the profile of a pendant drop using computer-aided image processing. J. Colloid Interface Sci. 1996, 184, 64-76.

(16) Rulon, J.; Robert, H. Wetting of Low-Energy Surfaces. In Wettability; Berg, J. C., Ed.; Marcel Dekker Inc.: New York, 1993; pp 4-73.

(17) Newman, A. W.; Kwok, D. Y. Contact angle measurement and contact angle interpretation. Adv. Colloid Interface Sci. 1999, 81, $167-249$.

(18) Guillard, V.; Broyart, B.; Bonazzi, C.; Guilbert, S.; Gontard, N. Preventing moisture transfer in a composite food using edible films: Experimental and mathematical study. J. Food Sci. 2003 68, 2267-2277.
(19) ASTM D 3985-05. Standard test method for oxygen gas transmission rate through plastic film and sheeting using a coulometric sensor. In ASTM Book of Standards; ASTM International: West Conshohocken, PA, 2005.

(20) Salvador, M. L.; Jaime, P.; Oria, R. Modeling of $\mathrm{O}_{2}$ and $\mathrm{CO}_{2}$ exchange dynamics in modified atmosphere packaging of burlat cherries. J. Food Sci. 2002, 67, 231-235.

(21) Owolarafe, O. K.; Olabige, T. M.; Faborode, M. O. Macrostructural characterization of palm fruit at different processing conditions. J. Food Eng. 2007, 79, 31-36.

(22) Di Marzo, S.; Di Monaco, R.; Cavella, S.; Romano, R.; Borriello, I.; Masi, P. Correlation between sensory and instrumental properties of Canestrato Pugliese slices packed in biodegradable films. Trends Food Sci. Technol. 2006, 17, 169-176.

(23) Yildirim, M.; Gülec, F.; Bayram, M.; Yildirim, Z. Properties of Kashar cheese coated with casein as carrier of natamycin. Ital. J. Food Sci. 2006, 18, 127-138.

(24) Van Oss, C. J. Hydrophobicity of biosurfaces: Origin, quantitative determination and interactions energies. Colloids Surf., B 1995, 5, 91-110.

(25) Garcia, M. A.; Martino, M. N.; Zaritzky, N. E. Lipid addition to improve barrier properties of edible starch-based films and coatings. J. Food Sci. 2000, 65, 941-947.

(26) Hernandez-Muñoz, P.; López-Rubio, A.; Del-Valle, V.; Almenar, E.; Gavara, R. Mechanical and water barrier properties of glutenin films influenced by storage time. J. Agric. Food Chem. 2004, 52, 79-83.

(27) Hong, S. I.; Krochta, J. M. Oxygen barrier properties of whey protein isolate coatings on polypropylene films. J. Food Sci. 2003, 68, 224-228.

(28) Avena-Bustillos, R. J.; Krochta, J. M. Water vapor permeability of caseinate-based edible films as affected by $\mathrm{pH}$, calcium crosslinking and lipid content. J. Food Sci. 1993, 58, 904-907.

(29) Péroval, C.; Debeaufort, F.; Despré, D.; Voilley, A. Edible arabinoxylan-based films. 1. Effects of lipid type on water vapor permeability, film structure, and other physical characteristics. $J$. Agric. Food Chem. 2002, 50, 3977-3983.

(30) Pranoto, Y.; Vilas, M. S.; Rakshit, S. K. Physical and antibacterial properties of alginate-based edible film incorporated with garlic oil. Food Res. Int. 2005, 38, 267-272.

(31) Caner, C.; Vergano, P. J.; Wiles, J. L. Chitosan film mechanical and permeation properties as affect by acid, plasticizer, and storage. J. Food Sci. 1998, 63, 1049-1053.

(32) Cuq, B.; Gontard, N.; Cuq, J. L.; Guilber, S. Functional properties of myofibrillar protein-based biopackaging as affected by film thickness. J. Food Sci. 1996, 61, 580-584.

(33) Yang, L.; Paulson, A. T. Effects of lipids on mechanical and moisture barrier properties of edible gellan film. Food Res. Int. 2000, 33, 571-578.

(34) Papaioannou, G.; Chouliara, I.; Karatapanis, A. E.; Kontominas, M. G.; Savvaidis, I. N. Shelf-like of a Greek whey cheese under modified atmosphere packaging. Int. Dairy J. 2007, 17, 358-364.

(35) Fedio, W. M.; Ozimek, L.; Wolfe, F. H. Gas production during storage of Swiss cheese. Milchwissenschaft 1994, 49, 3-8.

Received for review September 3, 2008. Revised manuscript received December 19, 2008. Accepted December 20, 2008. M.A.C. is a recipient of a fellowship from Fundação para a Ciência e Tecnologia (FCT, SFRH/BD/23897/2005), A.M.L. is the recipient of a fellowship from aLFA VALNATURA Project of the Europe Aid Cooperation Office, and B.W.S.S. is a recipient of a fellowship from the Coordenação Aperfeiçoamento de Pessoal de Nível Superior, Brazil (Capes, Brazil).

JF802726D 